\title{
The imperative of teaching professionalism to biomedical technologists
}

\author{
V Rambiritch, ${ }^{1}$ BTech Biomedical Technology, PGDip HPE, MPhil HPE; A Smith-Tolken, ${ }^{2}$ BA SocSc, MPhil, PhD \\ ${ }^{1}$ Learning and Development, South African National Blood Service, Johannesburg, South Africa \\ ${ }^{2}$ Department of Sociology and Social Anthropology, Faculty of Arts and Social Sciences, Stellenbosch University, Cape Town, South Africa
}

Corresponding author: A Smith-Tolken (asmi@sun.ac.za)

\begin{abstract}
Background. Biomedical technologists are key role players in the diagnosis of disease and serve as consultants for the appropriate use of medical laboratory services, making them essential partners in interprofessional healthcare. The blood transfusion biomedical technology national internship curriculum strongly emphasises knowledge and laboratory skills development. Very little has been published on research regarding biomedical technology interns' knowledge, understanding and development of professionalism, which prompted this study.

Objectives. To determine intern blood transfusion biomedical technologists' understanding of professionalism and to explore potential strategies for effective teaching of professionalism for improved practice.

Methods. A mixed-methods research design was used, consisting of a curriculum analysis, followed by a questionnaire in the quantitative phase of the study and focus group interviews in the qualitative phase. A statistical analysis of qualitative data indicated a trend in the perceptions of interns, while the qualitative data were thematically coded and analysed.

Results. Professionalism had different meanings for different individuals, but a strong focus on ethical conduct evolved. Professionalism in education was not only a deficiency in the internship curriculum, but was also absent in the various university undergraduate biomedical technology curricula. The need for structured teaching of professionalism was strongly supported by the interns and their educators. A host of active and interactive approaches to the teaching of professionalism was suggested to achieve the goal of elevating the role of biomedical technologists in the interprofessional healthcare approach.

Conclusions. Professionalism needs to be purposely taught to ensure a consistent understanding and to inform practice. Reviewing and upscaling of the internship and the university undergraduate biomedical technology curricula are needed to include explicit teaching of professionalism.
\end{abstract}

Afr J Health Professions Educ 2019;11(4):139-144. https://doi.org/10.7196/AJHPE.2019.v11i4.1101

Laboratory medicine is part of the total process of healthcare.$^{[1]}$ Biomedical technologists are an essential part of the interprofessional healthcare approach. They perform routine and complex laboratory tests, which guide clinicians in diagnosing diseases and treating patients. The role of biomedical technologists is changing at an unprecedented pace - from being mere providers of test results to becoming partners in healthcare. ${ }^{[2]}$

In South Africa (SA), the national diploma in biomedical technology is a 3-year university undergraduate qualification. An additional 1-year mandatory internship training at an accredited medical laboratory is a prerequisite to write the national board examination and for registration with the Health Professions Council of South Africa (HPCSA) as a qualified practitioner. The South African National Blood Service (SANBS) is an accredited training institution providing internship training in the discipline of blood transfusion.

Biomedical technologists need to have knowledge of a diverse group of medical specialties, as well as leadership skills and professional attributes that will enable them to function successfully in interdepartmental multidisciplinary healthcare teams ${ }^{[3]}$ - all aimed at quality patient care. Baingana et al. ${ }^{[4]}$ explain that patients entrust their health to healthcare workers, who are expected to have a high degree of professionalism. Professionalism is an integral part of clinical practice in allied health and medical fields ${ }^{[5]}$ and must be reinforced in health practitioners. ${ }^{[6]}$
Educational curricula are usually explicit in defining knowledge and skills development. Contrary to this, professionalism has traditionally been part of the hidden or informal curriculum and known to be 'caught rather than taught. ${ }^{\text {[4] }}$ The literature currently points to the growing threat of professional values and work standards being compromised in the medical and health science fields. ${ }^{[4,7,8]}$ Consequently, the need for improving instruction on professionalism in medical education ${ }^{[9]}$ is widely supported. One of the authors (VR), who is a health science educator at the SANBS, found that several students demonstrated poor professional behaviours during their internship training, which often persist as they progress into their careers. Failure to follow instructions, error rates, poor compliance to laboratory work standards and counselling of the interns by their superiors bear testimony to the identified poor attitudes, behaviour and work standards.

The broad aim of the study was to determine the interns' understanding of professionalism and to explore the need for structured teaching of professionalism. Gaining insight into the interns' perceptions was used as a needs analysis to upscale and strengthen the internship curriculum by including teaching of professionalism, as indicated by the study. As very little knowledge is available on the teaching of professionalism in the field of biomedical technology, the study also aimed to unpack what professionalism entails and how it should be taught. 


\section{Methods}

A mixed-methods design guided the study, consisting of a curriculum analysis, a questionnaire and focus group discussions. The questionnaire provided quantitative data using Likert-scale answers. It aimed at identifying trends related to how and where the respondents placed themselves in terms of understanding professionalism and their perspectives regarding the need for professionalism education. The focus group discussions that followed generated qualitative data regarding perceptions on what and how professionalism should be taught. The researcher (VR), who facilitated the focus group discussions, was not involved with teaching of the interns at the time of the study to ensure that respondents were not coerced into participation. Each participant completed and signed a consent form before participation. The sampling was purposive and included the interns and educators involved with internship training at the SANBS. All 54 interns enrolled in the SANBS internship programme across SA at the time of the study were invited to complete the questionnaire and participate in the focus group discussions. All 8 SANBS educators were invited to participate in a separate focus group discussion. Fifty interns completed the questionnaire, providing a response rate of $92.59 \%$. A total of 28 interns and 4 educators $(n=32)$ participated in 5 focus group discussions. The interns had completed their undergraduate biomedical technology studies at different universities in SA.

The quantitative data were statistically analysed, coded and categorised into themes. The qualitative data were coded through thematic analysis and categorised into themes. Both sets of data were compared through triangulation to develop the overall findings, which culminated into four main emerging themes that are presented in the findings in this article.

\section{Blood transfusion biomedical technology internship programme - curriculum analysis}

Curriculum defines the learning during a course or programme ${ }^{[10]}$ in terms of knowledge, skills and attitudes. Curriculum analysis provides an opportunity to evaluate the efficiency of a curriculum with regard to its content, appropriateness and instruction. The national internship curriculum was analysed according to an adapted version of Harden's 10 questions for curriculum analysis ${ }^{[11]}$ and is presented in Table 1.

\section{Ethical approval}

Ethical approval for the study was attained from the SANBS (ref. no. 2014/21) and Stellenbosch University Medicine and Health Sciences Research Ethics Committee (ref. no. S15/04/069).

\section{Results}

Table 2 shows the strengths and weaknesses of the internship curriculum by using the framework presented in Table 1 as a lens. The curriculum analysis showed adequate focus on technical knowledge and routine laboratory skills development. However, it was deficient in guiding the development of professional values, and also lacked guidelines for leadership development and mentorship models to guide and support students.

\begin{tabular}{ll} 
Table 1. Curriculum analysis framework applied to the blood transfusion biomedical technology curriculum \\
\hline No. & Question \\
\hline 1 & What is the purpose of the internship programme? \\
2 & Are the learning outcomes relevant and appropriate to the broad programme? \\
3 & Is the content adequate, relevant and is there enough time to ensure learning? \\
4 & Are the theoretical and practical learning areas of the programme appropriately integrated? \\
5 & What teaching strategies are applied to achieve outcomes and are they effective? \\
6 & Are there opportunities for structured teaching of professionalism, humanistic and ethical values? \\
7 & Are assessment methods fit for purpose in measuring outcomes? \\
8 & Do the educators have the knowledge, skills and resources to deliver the programme? \\
9 & Are there systems in place for guidance and support of learners?
\end{tabular}

\section{Table 2. Strengths and weaknesses of the internship curriculum}

\begin{tabular}{|c|c|}
\hline Strengths & Weaknesses \\
\hline $\begin{array}{l}\text { - The internship programme has a meaningful purpose that relates to the overall } \\
\text { broad biomedical technology programme, with strong technical and scientific } \\
\text { focus } \\
\text { - The learning outcomes are clear, specific and achievable within the duration of } \\
\text { the programme } \\
\text { - Resources needed for the development of routine practical laboratory skills are } \\
\text { appropriate and adequate } \\
\text { - Practical learning follows theoretical learning, which provides good integration } \\
\text { of learning } \\
\text { - Assessment methods for knowledge and practical assessments are fit for purpose } \\
\text { and appropriately matched to learning outcomes } \\
\text { - Opportunities for learner support and feedback are in place } \\
\text { - The educators have the knowledge and skills to guide and support learning }\end{array}$ & $\begin{array}{l}\text { - Overload of theoretical content in preparation for the national } \\
\text { board examination, with little focus on fieldwork experience } \\
\text { - Inadequate opportunities for development of non-routine/ } \\
\text { specialised practical laboratory skills } \\
\text { - Inadequate opportunities for critical analysis of laboratory } \\
\text { procedures and case study interpretations } \\
\text { - Lack of self- and peer assessment } \\
\text { - The same stakeholders routinely evaluate the curriculum } \\
\text { - Absence of outcomes related to development of student leadership } \\
\text { and of professional and humanistic values } \\
\text { - Absence of dedicated mentorship models }\end{array}$ \\
\hline
\end{tabular}




\section{Research}

A host of basic themes emerged from analysis of the quantitative and qualitative data. The basic themes were categorised into subthemes that evolved into 4 main themes. A breakdown of the basic themes, subthemes and main themes is presented in Fig. 1. Graphs containing the quantitative data indicate the preferences of respondents, while the qualitative data are discussed with direct quotes from respondents in the focus group discussions. In the findings, FG refers to the focus group and is used to link direct quotes from the respondents to the respective focus group

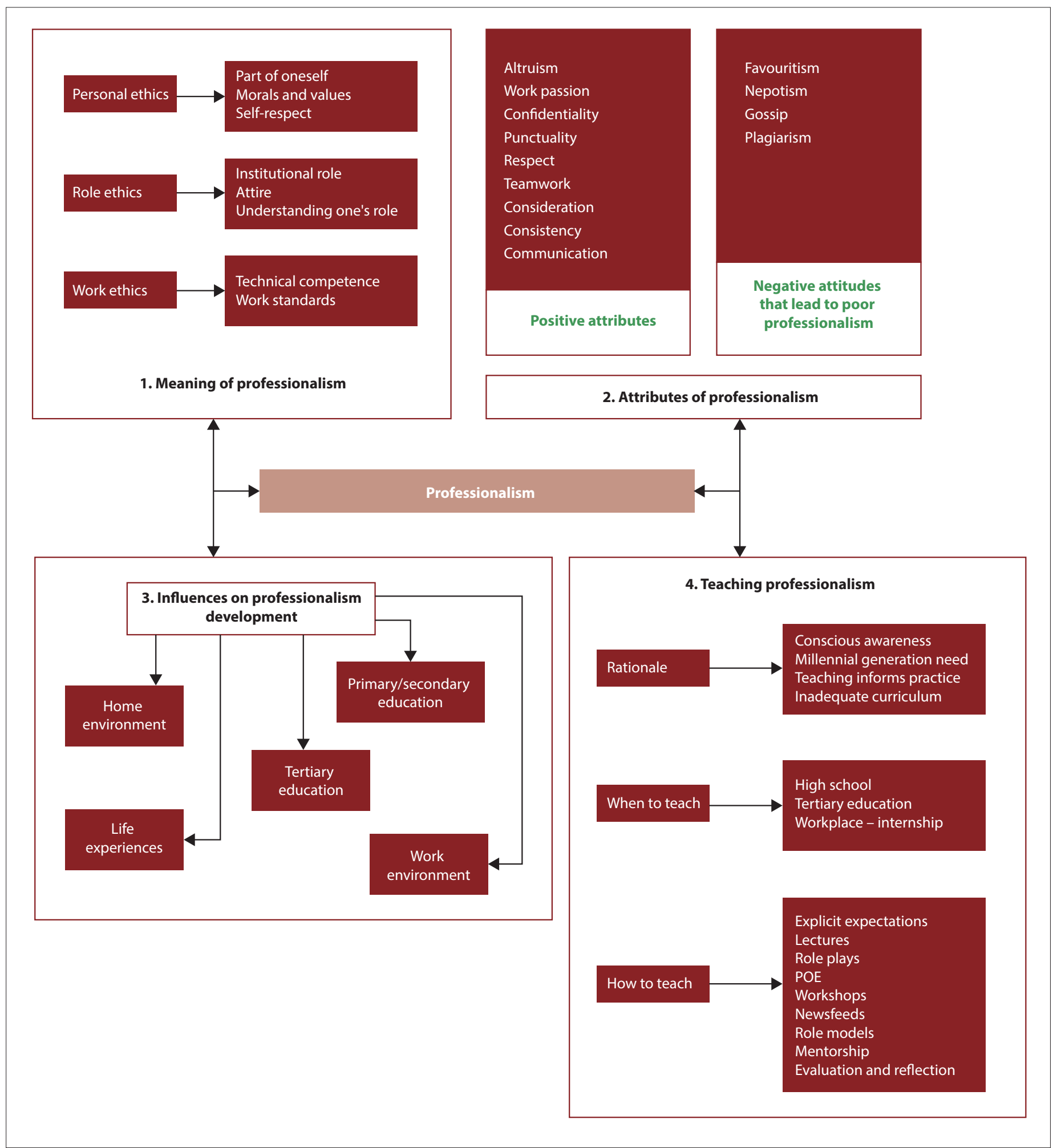

Fig. 1. Basic themes, subthemes and main themes. (POE = portfolio of evidence.) 
discussions. Focus groups $1-4$ included intern participants, while focus group 5 included educator participants. The quotes given below substantiate the statements that precede them regarding what is perceived as professional behaviour and identity.

\section{Theme 1: Meaning of professionalism}

The meaning of professionalism was equated with ethical behaviour and linked to professional role and identity. Some of the respondents perceived professionalism as relating to one's inherent morals and values, which form part of one's identity as a person:

'I also see professionalism as some sort of natural instinct ... our morals, your own values, your common sense as to what is right and wrong. (FG1)

Attire symbolises professionalism and contributes to one's professional role and identity, which serve to entrench public trust and faith in health professionals:

'Once you wear that uniform you must, you must show you are here to save a life, people must have faith in you and when people see us, they must have faith in us.' (FG2)

Technical competence is imperative to save lives by performing highstandard transfusion testing and providing safe, compatible blood for transfusion to patients:

'Professionalism would be to acknowledge that I am competent in what

I'm doing. I have the skills and knowledge behind it.' (FG1)

Ethical conduct manifested from understanding one's role and purpose within the profession. A sound understanding of that role encouraged ethical behaviour. Perceiving their role as essential in healthcare determines the way in which work ethics are maintained. The questionnaire responses showed that $100 \%$ of the respondents agreed that they had an essential role in healthcare. The focus groups, however, revealed that the interns and their educators felt that some biomedical technologists lacked an understanding of professionalism and the importance of their role in healthcare, which affected their attitudes and work standards:

'From their behaviour, I think some have an understanding of professionalism, but not everybody. I don't think they know where they fit in healthcare.' (FG5)

One of the roles of biomedical technologists is to advise other healthcare professionals with regard to laboratory testing and appropriate use of blood aimed at preventing blood wastage and reducing healthcare costs. Collaboration with doctors and providing them with guidance were sometimes challenging. Subsequently, professionalism meant more than being a biomedical technologist; it was about taking on a leadership and advisory role, despite such challenges:

'... some of them [the doctors] feel like you don't know what you are doing. Then when you tell them the right thing they respect you.' (FG3)

Negligence is perceived as a classic demonstration of poor work ethics that compromises work standards, with the potential to cause harm to patients. The interns indicated that some practitioners have a poor attitude and little fear of making errors, which could influence the wellbeing of patients:
'They don't follow the SOP [standing operating procedure]. Anything can happen to the patient ... that's unprofessional.' (FG4)

This theme concluded that professionalism had different meanings for different respondents, and was reflected in three distinct domains of personal ethics, role ethics and work ethics.

\section{Theme 2: Attributes of professionalism}

The respondents also described specific attributes that encourage positive professional development, and negative attitudes that hamper professionalism. The essential positive attributes of professionalism included altruism, work passion, commitment, dedication, confidentiality, punctuality, respect, teamwork, consistency, being considerate and good communication skills:

'I would say commitment and dedication; it goes with your passion for work.' (FG3)

The inverse of the abovementioned positive attributes constituted unprofessional behaviour; such behaviours impacted negatively on the work environment. Negative behaviours described by participants included nepotism, favouritism, plagiarism and gossip:

'You create a bad environment when you end up having people who gossip about each other'. (FG4)

Overall, the interns showed good awareness of the required professional attributes and inappropriate negative attitudes.

\section{Theme 3: Influence on development of professionalism}

Fig. 2 shows that several factors influenced the interns' understanding of professionalism. The work environment, however, emerged as the most dominant determinant.

The interns ascribed their exposure to both positive and negative behaviours in the workplace. Negative attributes demonstrated by colleagues had a negative influence on the conduct of some interns, while good role modelling by some practitioners contributed positively to the professional development of other interns:

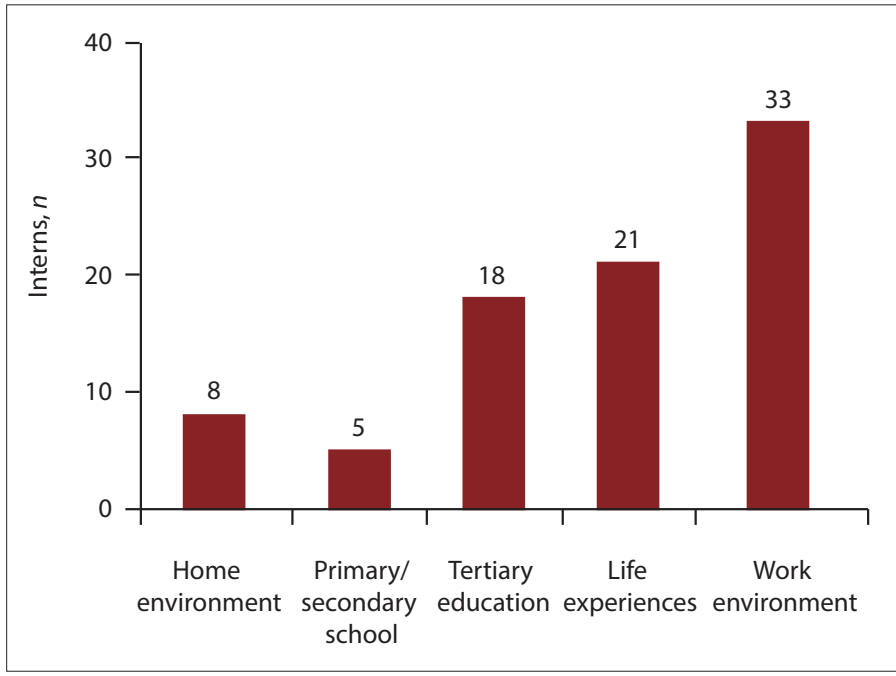

Fig. 2. Influences on the understanding of professionalism $(\mathrm{n}=50)$. 
'The way they carried themselves, the commitment that they had for their work ... this is what I'm here for. Now they showed professionalism.' (FG4)

In addition to the attitudes and behaviours of workplace colleagues influencing the interns, intrinsic factors such as their upbringing, morals, values, selfreflection and reflection on workplace activities also contributed to their development of professionalism:

'... your upbringing, your morals, your own values, your common sense as to what differs to what, your resistance to stay true to what you believe in. (FG1)

\section{Theme 4: Teaching professionalism}

The questionnaire responses indicated that $40 \%$ of the respondents had been exposed to some education on professionalism development. However, $82 \%$ indicated the need for formal teaching of professionalism. Exploring the rationale for teaching professionalism, the interns and educators responded differently. Interns indicated that professionalism should be taught to instil conscious awareness of appropriate behaviours and conduct; it must be taught for it to be applied. The educators felt that professional values were not inherent in millennials; hence the need to teach these:

'... the old school people they came with those values. They didn't have to be taught, it was part of them naturally.' (FG5)

The educators' perceptions of millennials were interpreted as bias because no substantial evidence was provided to support their views. The literature points to professionalism deteriorating globally, ${ }^{[7]}$ but there is no scientific evidence to categorise millennials as a particular group lacking professionalism.

The educators' feedback on the imbalances that existed in the internship curriculum offered a useful perspective. They pointed out the dominant focus on technical knowledge and practical skills development, with inadequate opportunities for the development of humanistic values and people skills:

'... also the focus of the training is knowledge and skills.' (FG5)

'They have the knowledge and skills but they can't communicate properly'. (FG5)

There was agreement among interns that professionalism education should be included in the life-orientation curriculum for secondary school education. It should also be taught during tertiary education to ensure readiness for the world of work. Teaching professionalism should start early in the biomedical undergraduate programme and not on an exit level of the study programme or at the time of work-integrated and internship learning, as currently:

'Don't wait for that experiential training, because that is not going to work.

They need to know from the beginning. (FG3)

Probing the 'how' of teaching professionalism revealed an extensive list of teaching methods, including activities that could be used, supported by a quote from the respondents in the focus groups. Table 3 presents a list of teaching approaches that emerged from the focus groups.

\section{Discussion and recommendations}

Professionalism had different meanings for different individuals - no consistent definition emerged. Ethical behaviour, however, stood out as a strong indicator of professionalism. A previous study reported similar interpretations of professionalism where definitions differed within and between various health professional groups, thus making professionalism conceptually unclear. ${ }^{[12]}$ Although no one common meaning of professionalism emerged, one common thread linking the domains of understanding surfaced in the study. The need to do what is right for the patient formed the central core upon which professionalism was defined - where doing what is right for the patient requires an appropriate make-up of behaviours that contribute to saving lives. When a person joins the healthcare profession, they should have a clear concept of their professional identity and their roles and responsibilities, and bring with them certain non-negotiable 'must-have' attributes, such as altruism and work passion. The essential positive attributes of professionalism described by the interns closely resemble the required attributes for health practitioners described in the literature. ${ }^{[4,9,12]}$

Role models in the work environment presented with positive and negative influences, having a dual impact on the professional development of some of the interns. Baingana et al. ${ }^{[4]}$ explain that students' participation in unprofessional conduct is linked to witnessing unprofessional conduct, with an enhanced likelihood of them viewing these behaviours as acceptable and thus creating a cycle that entrenches unprofessional conduct. What students hear in the classroom does not make the most durable impression; what they see and hear in everyday practice of those in the profession etches their attitudes and hardens their perceptions about the real expectations of the profession. ${ }^{[9]}$ The work environment is therefore a powerful stage, not only for technical expertise development, but also for professional development.

Professionalism education was absent in the university biomedical technology undergraduate curricula. The need for structured teaching of professionalism through the formal curriculum surfaced as a strong imperative. Ongoing education was called for as a means to create conscious awareness of professionalism and its associated attributes. What may seem common sense for some is not common sense for all; hence the need to teach professionalism.

Swick ${ }^{[13]}$ advocates a normative definition of professionalism - one that is simple, yet comprehensive, and that allows for consistent understanding of professionalism. A possible definition that the researchers saw emerging from the meanings provided was: 'Professionalism is a combination of values and attitudes that inform behaviours and interactions that serve as the foundation for good ethical practices as a duty to patients and to society.' Such a definition can serve as a consistent and robust thread linking teaching and learning at all the phases of studying for a profession.

Defining the role of biomedical technologists, and how they fit in the collaborative interprofessional healthcare approach through interprofessional education, is strongly recommended in future research. Educational partnerships with medical and health science faculties to allow biomedical technology students to collaborate and learn with other health professional disciplines during their study, should become a commitment on the part of their future employers. Opportunities for students and interns to have some monitored exposure to patients during their study will allow better conceptualisation of their healthcare roles. It will support the development of their professional identity and improve understanding of how their attitudes, behaviours and work practices affect patients.

Leadership development and explicit teaching of professionalism should be incorporated into the curricula for the Bachelor of Health Science (BHSc) degree, which soon replaces the national diploma in biomedical technology. The various stakeholders involved in the education of biomedical technologists at all levels of study, as well as university-led advisory boards and education committees, need to partner in the curricula reform process. The approaches to teaching professionalism suggested in this study should be analysed, tailored and integrated into the 
Table 3. Teaching approaches that emerged from the focus groups

\begin{tabular}{|c|c|c|}
\hline Method & Activities & Quotes from respondents \\
\hline Lectures & Presentations & FG1: 'Lectures are a good start.' \\
\hline Group discussion & $\begin{array}{l}\text { Providing clarity on work responsibilities and professional } \\
\text { obligations }\end{array}$ & FG2: '... knowing what is expected of them.' \\
\hline Role play & Active practice learning through scenario setting & $\begin{array}{l}\text { FG1: '... given scenarios and act out how they would conduct } \\
\text { themselves professionally and that way they can be corrected } \\
\text { as to what is the right way to act professional in different } \\
\text { situations.' }\end{array}$ \\
\hline Portfolio & $\begin{array}{l}\text { Documenting experiences and observations associated with } \\
\text { good and poor professionalism } \\
\text { Bad experiences can create tension }\end{array}$ & $\begin{array}{l}\text { FG4: 'I've collected all my evidence. What happens to these } \\
\text { bad experiences? It's a bad idea because everyone will be on } \\
\text { edge in the lab now.' }\end{array}$ \\
\hline Educator-facilitated workshop & $\begin{array}{l}\text { Sharing learning experiences } \\
\text { Defining appropriate and inappropriate behaviour }\end{array}$ & $\begin{array}{l}\text { FG2: 'We can have workshops just to tell people what is } \\
\text { expected of them and we can talk about what affects us in the } \\
\text { workplace ... someone can actually change their attitude.' }\end{array}$ \\
\hline News feed & $\begin{array}{l}\text { Acknowledging or congratulating practitioners for their } \\
\text { good professional deeds could inspire others to follow suit }\end{array}$ & $\begin{array}{l}\text { FG3: 'Oh, well done for going the extra mile on this, this, and } \\
\text { this and it will be circulated. }\end{array}$ \\
\hline Mentoring & $\begin{array}{l}\text { Appointing mentors to novice practitioners } \\
\text { Mentors support, educate and guide }\end{array}$ & $\begin{array}{l}\text { FG4: '... have mentors, they have a lot of influence in shaping } \\
\text { you to being your best.' }\end{array}$ \\
\hline $\begin{array}{l}\text { Peer-assisted learning and } \\
\text { reflection }\end{array}$ & $\begin{array}{l}\text { Seniors complete questionnaires evaluating the interns' } \\
\text { professional conduct } \\
\text { Interns reflect on their own attitudes and behaviours and } \\
\text { complete a similar self-evaluation questionnaire }\end{array}$ & $\begin{array}{l}\text { FG5: '... a questionnaire where the supervisor will reflect and } \\
\text { report on the student attributes and the student will reflect } \\
\text { and report.' }\end{array}$ \\
\hline Online CPD platform & Case study analysis & $\begin{array}{l}\text { FG5: 'Yes CPD. It should not just be information on } \\
\text { professionalism; case studies could be used. I think that will } \\
\text { be more effective and meaningful.' }\end{array}$ \\
\hline Exposure to real-life situations & $\begin{array}{l}\text { Field trips to hospitals - interacting with patients and other } \\
\text { healthcare professionals }\end{array}$ & $\begin{array}{l}\text { FG5: 'Take them on a session where they can go to a hospital } \\
\text { and see patients that are on chronic transfusion programmes } \\
\ldots \text { It will create an emotion and emotion will become a } \\
\text { lifelong commitment.' }\end{array}$ \\
\hline
\end{tabular}

$\mathrm{CPD}=$ continuing professional development.

curricula as a continuum of ongoing learning. 'Development of professionalism is a continuum and a realization that proper standards of professional behaviour have to sustain for a lifetime. ${ }^{\text {?[] }}$ Once-off teaching of professionalism is therefore not a solution. Opportunities for reflection on learning experiences, which contribute to deep learning, should be incorporated in curricula. ${ }^{[14]}$

Capacity building for educators, those in leadership roles and those who serve as role models, as means to provide readiness to embrace and deliver the outcomes of the redefined curricula, emerged as a need. A value proposition of this study is that a national competency framework model similar to the Canadian Medical Education Directives for Specialists (CanMEDS) model ${ }^{[15]}$ be developed to serve as a blueprint guiding the development of knowledge, skills, behaviours and leadership of biomedical technologists in SA and elsewhere.

\section{Conclusions}

Curriculum is essential in directing the teaching and learning of professionalism. A once-off evaluation of the curriculum, however, is not the solution; ongoing review is needed to support meaningful learning directed towards the development of well-rounded future health professionals.

Declaration. The research was a requirement for VR's MPhil HPE degree, but the publication was not a requirement for the degree.

Acknowledgements. The authors thank the intern and educator study respondents at the South African National Blood Service for their participation in the study.
Author contributions. AS was VR's study leader. The authors contributed equally to the writing of the article.

Funding. None.

Conflicts of interest. None.

1. Plebani M. The clinical importance of laboratory reasoning. Clin Chim Acta 1999;280(1-2):35-45.

2. Plebani M. Charting the course of medical laboratories in a changing environment. Clin Chim Acta 2002;319(2):87-100.

3. Panteghini M. The future of laboratory medicine: Understanding the new pressures. Clin Biochen 2004;25(4):207-215.

4. Baingana RK, Nakasuija N, Galukande M, Omona K, Mafigiri DK, Sewankambo NK. Learning health professionalism at Makerere University: An exploratory study amongst undergraduate students. BMC Med Educ 2010;10:76. https://doi.org/10.1186/1472-6920-10-76

5. Tsoumas LT, Pelletier D. Integrating professional behaviour across a professional allied health curriculum. J Allied Health 2007;36(4):e313-e325.

6. Wear D, Castellani B. Development of professionalism: Curriculum matters. Acad Med 2000;75(6):602-611. 7. Cruess RL, Creuss SR. Teaching professionalism: General principles. Med Teach 2006;28(3):205-208. https://doi org $/ 10.1080 / 01421590600643653$

8. Frenk J, Chen L, Bhutta Z, et al. Health professionals for a new century: Transforming education to strengthen health systems in an independent world. Lancet 2010;376(9756):1923-1956. https://doi.org/10.1016/S01406736(10)61854-5

9. Cohen JJ. Professionalism in medical education, an American perspective: From evidence to accountability. Med Educ 2006;40(7):607-617. https://doi.org/10.1111/j.1365-2929.2006.02512.x

10. McKimm J. Curriculum design and development. 2003. www.faculty.londondeanery.ac.uk curriculum Jesignandderop (occesed 5 September 2016).

1. Harden RM. Ten questions to ask when planning a course or curriculum. Med Educ 1986:20:356-365.

12. Burford B, Morrow G, Rothwell C, Carter M, Illing J. Professionalism education should reflect reality: Findings from three health professions. Med Educ 2014;48(4):361-374. https://doi.org/10.1111/medu.12368 3. Swick HM. Toward a normative definition of medical professionalism. Acad Med 2000;75(6):612-616.

13. Swick HM. Toward a normative definition of medical professionalism. Acad Med 2000;75(6):612-616.
14. Haggis T. Constructing images of ourselves? A critical investigation into 'approaches to learning' research in Haggis T. Constructing images of ourselves? A critical investigation into 'approaches to learning
higher education. Brit Educ Res J 2003;29(1):89-104. https://doi.org/10.1080/0141192032000057401 15. Frank JR. The CanMEDS 2005 Physician Competency Framework. Better Standards. Better Physicians. Better Care. 5. Frank JR. The CanMEDS 2005 Physician Competency Framework. Better
Ottawa: Royal College of Physicians and Surgeons of Canada, 2005.

Accepted 1 July 2019. 